\title{
Unravelling the Cipher of Indian Rupee's Volatility: Testing the Forecasting Efficacy of the Rolling Symmetric and Asymmetric GARCH Models
}

\author{
Shalini Talwar*, Aparna Bhat \\ Department of Finance, K J Somaiya Institute of Management Studies and Research, Mumbai, India \\ Email: *shalini.t@somaiya.edu
}

How to cite this paper: Talwar, S. and Bhat, A. (2018) Unravelling the Cipher of Indian Rupee's Volatility: Testing the Forecasting Efficacy of the Rolling Symmetric and Asymmetric GARCH Models. Theoretical Economics Letters, 8, 1188-1217. https://doi.org/10.4236/tel.2018.86079

Received: February 25, 2018

Accepted: April 20, 2018

Published: April 23, 2018

Copyright $\odot 2018$ by authors and Scientific Research Publishing Inc. This work is licensed under the Creative Commons Attribution International License (CC BY 4.0).

http://creativecommons.org/licenses/by/4.0/

\begin{abstract}
Modelling exchange rate volatility is crucially important because of its diverse implications on the profitability of corporations and decisions of policy makers. This paper empirically investigates exchange rate volatility of India's currency by applying rolling symmetric and asymmetric GARCH models to the USDINR and EURINR daily exchange rates for a period spanning April 1, 2006 through January 31, 2018, resulting in total observations of 2861. To estimate GARCH $(1,1)$ and EGARCH $(1,1)$ models, the data window is rolled over five years with nearly 1200 observations and one month is used as forecast period for each window. Both, in-sample criteria like the log likelihood criteria, Akaike information criterion (AIC), the Bayesian information criterion (SIC) and Hannan Quinn criterion (HQC) as well as the out-of-sample criteria like Mean Squared Error (MSE) and Mean Absolute Error (MAE) have been used to test model fit and forecast accuracy of the models. To test the robustness of the findings, Diebold-Mariano test is used to compare the predictive accuracy of both the models. Further, the forecasting accuracy of the two models has also been tested by splitting the sample period into periods of tranquility and volatility in Indian exchange rate. Results show that GARCH $(1,1)$ model with generalized error distribution is adequate to capture the mean and volatility process of USDINR and EURINR exchange rate returns.
\end{abstract}

\section{Keywords}

Diebold-Mariano Test, Exchange Rate Volatility, GARCH Models, Generalized Error Distribution, Heteroscedasticity 


\section{Introduction}

The assumption of homoscedasticity or constancy of variance over time is inappropriate as it is now an established fact that the variance of financial time series like exchange rate and stock price data is not constant. The volatility of any financial time series is dynamic and time-varying and any attempt to forecast it with acceptable accuracy requires application of models that have heteroscedasticity as their underlying assumption. Models based Autoregressive Conditional Heteroscedasticity (ARCH) given by [1] and its generalized variant ( $\mathrm{GARCH})$ given by [2] capture the dynamic nature of time series volatility quite effectively. Further, the GARCH family models also accommodate a more flexible lag structure as they model error variance by an Autoregressive Moving Average (ARMA) type process. With the result, the use of GARCH family models has become quite popular among researchers and analysts for modelling volatility of financial time series.

In this paper, the authors endeavor to demystify the evolving behavior of India's currency vis-à-vis two currency majors by applying rolling symmetric and asymmetric GARCH models to the USDINR and EURINR time series for a period spanning April 1, 2006 through January 31, 2018. Year 2006 has been chosen as the beginning point of the data under the study to capture stability in rupee movement before the turbulence of 2008 set in. The period under the study is of particular interest as many significant economic events have taken place during this time. The world was recovering quite effectively from the $\mathrm{Y} 2 \mathrm{~K}$ crisis and it recorded annual GDP growth of 4.31 percent in 2006 and 4.25 percent in 2007 when the global financial crisis of 2008 reared its head. The world economy was still grappling with the aftermath of the global financial crisis of 2008 when the sovereign debt crisis surfaced in 2011 and drove the currencies around the globe in a tizzy. The global economy continued its metamorphosis and the world experienced lack-luster economic growth in 2014, with major slowing down of the emerging economies China, Brazil and Russia [3], followed by the shock of the Brexit debate in 2016. The global economy seems to be getting back on track as the World Economic Outlook report has projected a growth in global output by 3.5 percent in 2017 and 3.6 percent in 2018 [4].

In India, this period has been equally interesting with Indian economy exhibiting resilience in the face extreme challenges of global meltdown in 2008 to its slowing down gradually as sovereign debt crisis surfaced. Politics remained at the forefront in all economy related discourses, with 2014 becoming a special year in history of India. In 2016, the sovereign government in India announced 'demonetization' of legal tender in many denominations, unleashing a wave of economic uncertainty. The latest structural reform in the form of the introduction of goods and services tax (GST) in 2017 has added yet another dimension to the maturing of Indian economy. In the backdrop of such economic evolution, INR's exchange rate was writing its own destiny by going through phases of volatility and stability. The period chosen for the study offers many interesting ob- 
servations related to INR's volatility, resulting in new learnings for analysts, traders and investors.

The objective of this paper is to generate a series of equations using GARCH family variants estimated via Bayesian and maximum likelihood techniques by rolling the data window over the time period of the study. The authors have used GARCH $(1,1)$ and EGARCH $(1,1)$ based on generalized error distribution (GED), introduced by [5], as the past research in the field has revealed that of all the GARCH family models, the most promising models are the univariate GARCH $(1,1)$ and the asymmetric EGARCH $(1,1)$ model which captures the leverage effect. GED is used in the study because many past studies including one by [6] using GARCH $(1,1)$ to model exchange rate volatility under the distributional assumptions of GED and the Student's-t distribution have found the forecasting accuracy of the model with GED errors better.

The estimated models can be assessed by applying in-sample criteria like the log likelihood criteria, Akaike information criterion (AIC) [7], the Bayesian information criterion (BIC) [8] and Hannan Quinn (HQ) criterion [9]. However, the GARCH type models, given their utility, are best evaluated by ascertaining the robustness of out-of-sample forecasting. In the current study, the authors have applied Mean Squared Error (MSE) as a measure of forecasting accuracy, notwithstanding the suggestion of [10] that it might be a misleading indicator of average error. Use of RMSE/MSE has found a lot of support in the literature [11], [12]. Mean Absolute Error (MAE) has also been calculated to evaluate the efficacy of forecasting. Both these measures have been used by many previous studies including [6] and [13] amongst others. Thereafter, the Diebold-Mariano [14] test, henceforth $\mathrm{DM}$, is used to compare the predictive accuracy of both the models over the entire sample period. Further, the robustness of the findings of the study has been tested by examining the forecasting accuracy of both models over periods of volatility and tranquility in Indian exchange rate.

Both symmetric and asymmetric GARCH models of only first order have been used as it has been observed that financial time series tends to be well-behaved and one lagged error square term and one autoregressive term is usually more than adequate to capture the volatility. Low order GARCH models not only satisfy the statistical rule of parsimonious parameterization but also have comparatively superior numerical stability of estimation. GARCH models lag order $(1,1)$ is sufficient to model volatility as indicated by [15].

The current study, undertaken with a view to deeply diagnose the volatility of INR and attempt to generate an equation for forecasting INR values with acceptable accuracy, revealed that the forecast accuracy of the GARCH $(1,1)$ model is superior, based on MSE for both currency pairs. However, the MAE of the EGARCH $(1,1)$ model is seen to be lower in case of the USDINR pair.

Although the GARCH $(1,1)$ model appears to be superior to the EGARCH $(1,1)$ model on the grounds of lower MSE for both currency pairs and lower MAE for EURINR, yet based on the DM test statistics, the GARCH $(1,1)$ and the EGARCH $(1,1)$ appear to perform equally well in the context of the USDINR 
and the EGARCH $(1,1)$ appears to have slightly higher forecasting accuracy than the GARCH $(1,1)$ model in the context of the EURINR. However, the authors have recommended GARCH $(1,1)$ for both the series under the study as it has scored well on both, the out-of-sample forecasting accuracy as well as the in-sample model fit criteria.

This study is expected to be useful for international investors, risk managers and traders seeking to forecast rupee volatility. The empirical findings of the study can help analysts keen on using conditional volatility models for taking better currency investment decisions. The study is expected to benefit researchers in the field, both in the application of the GARCH-family models and evaluation of their forecasting accuracy. Knowledge of the models and method that can provide the most accurate forecasts for a given financial time series is important as such generalizations may form the basis of decision making by organizations that often rely upon a single method for a given data.

The study makes meaningful contribution to the existing research in the field as, to the best of the knowledge of the authors, very few GARCH-based studies have used the DM test and robustness test by splitting the sample period into periods of tranquility and volatility, particularly for the Indian rupee.

The remaining paper is organized as follows. Section 2 provides a brief overview of the past research in the field and Section 3 elaborates the methodology used to generate and compare the forecasting performance of the GARCH and EGARCH models with GED. Section 4 describes the data set used in this study. Section 5 gives analysis of empirical results, and Section 6 provides summary, conclusion, limitations of the study and scope for further research.

\section{Literature Review}

Volatility of financial time series has received considerable attention from researchers, both in the developed as well as the emerging economies. In fact, a large quantum of research work in financial time series is skewed towards the application of econometric tools to model time varying volatility. With the acceptance of the heteroskedastic nature of volatility, the use of autoregressive models for financial time series has become observably prevalent in theory and practice in the last two decades. The authors have reviewed a large number of studies to understand the processes and issues related to the application of GARCH models, particular for modelling the volatility of financial time series. Some of those studies are discussed in this section.

Reference [16] employed univariate GARCH and EGARCH models to test the persistence and asymmetry of exchange rate volatility of U.S. Dollar with reference to the Euro and the British Pound. The study revealed that both exchange rates exhibited asymmetric behavior, with the impact of negative shock being relatively more than the impact of positive shock.

Linear $\operatorname{GARCH}(1 ; 1)$ and threshold $\operatorname{GARCH}(1 ; 1 ; 1)$ processes were used by [17] in his study to establish the asymptotic properties of certain GARCH estimators. 
Reference [18] used EGARCH model for volatility forecasts and showed that they may be improved by inserting an additional regressor in the volatility equation. The study revealed that the inclusion of realized range-based measures as exogenous variables reduced persistence and left the past squared returns with no residual explanatory power.

The use of GARCH type models to investigate and forecast volatility of financial time series is documented in many more recent studies, for instance, [19], [20] and [21]. These studies applied the ARCH-type models to intra-day and daily data to study the volatility of indices, stocks and other financial time series.

The research in GARCH family models was taken further by [22] by providing a consistent specification test for generalized autoregressive conditional heteroskedastic (GARCH $(1,1))$ models based on a test statistic of Cramér-von Mises type.

Reference [23] investigated the performance of many commonly used GARCH models for fitting the rate of returns data for Nigerian stock market. The conclusions drawn using Log Likelihood (Log L), Schwarz Bayesian Criterion $(\mathrm{SBC})$ and the Akaike Information Criterion (AIC) indicated that the models identified were different for training and testing period.

Symmetric GARCH $(1,1)$ and asymmetric models EGARCH and GJR-GARCH models were used by [24] to study the symmetric and asymmetric response of exchange rate volatility. The study found that negative shocks led to higher volatility as compared to positive shocks. The study also compared in-sample forecasts from many GARCH models with the implied volatility derived from currency options for four dollar parities.

Daily stock returns from the Stockholm Stock Exchange were used by [25] to examine their volatility using GARCH $(1,1)$, EGARCH $(1,1)$ and GJR-GARCH $(1,1)$ with different residual distributions. The study found that negative shocks had a larger impact than the positive shocks in the market under the study.

Univariate nonlinear time series analysis was applied by [13] to the daily (TZS/USD) exchange rate data spanning from January 4, 2009 to July 27, 2015 to examine the behavior of the exchange rate in Tanzania. Both ARCH and GARCH models were used. Exponential GARCH (EGARCH) model was employed to capture the asymmetry in volatility clustering and the leverage effect in the Tanzanian exchange rate. The paper revealed that exchange rate under the study exhibited empirical characteristics such as clustering volatility, nonstationarity, nonnormality and serial correlation that are essential pre-conditions to apply GARCH. The study found that positive shocks implied higher next period volatility as compared to negative shocks of the same magnitude.

The Australian equity market's ultra-high-frequency data was used by [26] to construct an unbiased ex-post volatility GARCH based estimator and evaluated various practical volatility forecasting strategies. The study revealed that the forecasting errors across all models reduced when unbiased ex-post volatility estimator was used as compared with those modelled using the realized volatility based on intra-day data. The study found that the asymmetric power ARCH 
(APARCH) model exhibited the best forecasting power in both normal and financial turmoil periods in the Australian stock market.

Reference [27] used GARCH to model rupee volatility and its impact across Indian stock market as represented by Nifty. The mean equation of the model confirmed that appreciation in Indian rupee led to more funds in the stock market. The study also confirmed the persistence of volatility shocks between the stock market and the currency market. The study also revealed that the policymakers can indirectly intervene in stock market through monetary policy measures.

GARCH $(1,1)$ was used by [28] to measure real exchange rate volatility of Nigerian currency with a view to investigate the asymmetric effects of real exchange rate volatility on agricultural products export in Nigeria. Asymmetric effects test based on the Wald statistic showed that apart from cotton exports, the effect of currency volatility on cocoa, coffee and rubber exports was significantly different. The study concluded that in Nigeria, the real exchange rate volatility had noticeable impact on export of agricultural products.

The effects of the Czech National Bank communication, macroeconomic news and interest rate differential on exchange rate volatility was examined by [29] using GARCH. The results of the study showed that the central bank communication had a calming effect on exchange rate volatility. Further, macroeconomic news releases were observed to reduce exchange rate volatility, while interest rate differential seemed to increase it. The timing of communication by the central bank was also found to be important by the study, as financial markets responded more to it before the policy meetings than after it.

GARCH model was estimated by [30] for a large set of both weighted (export and trade) as well as unweighted (official and black market) real exchange rate series in India and found evidence of dimensionally weak and statistically insignificant ARCH effect as compared to GARCH effect in almost all the exchange rate series. The estimates of GARCH model were found to be sensitive to the measure of exchange rate used.

Reference [31] attempted to investigate the effectiveness of the Reserve Bank of India's (RBI) intervention policy in the foreign exchange market and tried to capture the volatility spillover between intervention and exchange rate using GARCH. The estimated model indicated that the RBI leaned against the wind in response to appreciating and depreciating pressure on rupee; thereby confirming no asymmetry in intervention. Good news was, however, found to have a significant negative impact on exchange rate as it tended to put pressure on the exchange rate to appreciate. The study observed that where intervention seemed to reduce exchange rate volatility, news seemed to trigger it. The estimated models also showed that the past volatility of exchange rate increased the present volatility of intervention.

Reference [32] also used GARCH model to estimate the volatility of Nairobi Securities Exchange (NSE). Many other studies have also applied symmetric and asymmetric GARCH variants to estimate and forecast the volatility of world 
currencies and other financial time series. The present study takes forward the same research to apply GARCH-family models to estimate the conditional volatility of the Indian rupee against the US dollar and the euro and evaluate the adequacy of these models in dynamic forecasting of rupee exchange rate volatility. The study has an added advantage of being based on more recent data as compared to the earlier studies.

\section{Methodology}

The study proposes to apply ARMA representation of GARCH $(1,1)$ and EGARCH $(1,1)$ for modelling conditional volatility of USDINR and EURINR time series. This section describes the mathematical implication of these two models. Before applying the GARCH estimators, certain diagnostic tests need to be conducted to ensure the suitability of data for GARCH modelling. In the current study, tests for testing stationarity of data, volatility clustering, heteroscedasticity and nonnormality have been applied to investigate if the data being used for modelling GARCH family models meets the requisite pre-conditions. The tests used for this purpose are also described in this section.

\subsection{Unit Root Test}

Existence of unit root is a primary concern in all financial series that have to be regressed to estimate meaningful and statistically valid coefficients. A time series with no unit root at levels or price is called integrated of Order 0 or said to follow I (0) process. However, most financial time series follow I (1) process i.e. they are nonstationary at levels but stationary at first difference. The two exchange rate series under the study have first been tested for nonstationarity or unit root using the Augmented Dickey-Fuller (ADF) test [33] [34] and Philips-Perron (PP) test [35]. These two tests test the null hypothesis of unit root against the alternative hypothesis of stationarity. The null is rejected if the value of probability is less than 0.05 for the test statistic thus computed. The models to test unit root are specified as follows:

Model (1)

$$
Y_{t}=A(0)+A(1) Y_{t}+e_{t}
$$

Test Statistics

$$
\begin{gathered}
\mathrm{H}_{\mathrm{o}}: \quad A(0)=A(1)=0 \quad \phi_{1} \\
A(1)=0 \quad \tau_{\mu}
\end{gathered}
$$

Model (2)

$$
Y_{t}=A(0)+A(1) Y_{t-1}+A(2)_{t}+e_{t}
$$

Test Statistics

$$
\begin{gathered}
\mathrm{H}_{\mathrm{o}}: A(0)=A(1)=A(2)=0 \quad \phi_{2} \\
A(1)=A(2)=0 \quad \phi_{3} \\
A(1)=0 \quad \tau_{\tau}
\end{gathered}
$$




$$
\begin{aligned}
& A(0)=0 \Rightarrow \text { No constant/drift } \\
& A(1)=0 \Rightarrow \text { Presence of unit root }(1-\rho)=A(1) \\
& A(2)=0 \Rightarrow \text { No trend }
\end{aligned}
$$

Lag length is also an important factor in these tests as it can impact the results. Lag length is usually determined using three main methods, namely, Akaike, Schwarz and Hannan-Quinn, which are considered to be the classical procedures for determining lag length as discussed by [36]. The current study has used Schwarz Information Criterion as the lag length criterion because it is the severest in penalizing loss of degree of freedom by including more parameters in the integral model. The AIC is the least rigid of the three and the HQ lies in between as it holds the middle ground in penalizing the loss of degrees of freedom.

\subsection{Volatility Clustering, ARCH Effect and Nonnormality of Distribution}

Further, few preconditions for application of GARCH family models for volatility estimation, namely, volatility clustering, the existence of ARCH effect and the nonnormality of distribution of residuals are also checked. Volatility clustering refers to the persistence of volatility, i.e. a characteristic of time series where a period of high volatility is followed by more volatility and that of tranquility is followed by more tranquility as discussed by [37]. In the current study, volatility clustering is confirmed visually by plotting the residuals of USDINR and EURINR series.

The presence of ARCH effect or autocorrelation of residuals is tested using the ARCH-LM test in which the statistical significance of Breusch-Godfrey LM test statistic is used to test the null of no serial correlation. Additionally, Ljung Box Q-statistics [38] [39] is also used to test for null of no serial correlation up to $\mathrm{p}$ lags. Low value of $\mathrm{p}$ (below 0.05 ) is used to reject the null and confirm the existence of ARCH effect or serial correlation in the series. The Ljung-Box test is based on the statistic given in Equation (3).

$$
Q^{*}=T(T+2) \sum_{k=}^{h}(T-k)^{-1} r_{k}^{2}
$$

where

$T$ is the length of the time series

$r_{k}^{2}$ is the $k^{\text {th }}$ autocorrelation coefficient of the residuals

$h$ is the number of lags to test

High values of $Q^{*}$ imply existence of significant autocorrelations in the residual series. It can be tested against a $\chi^{2}$ distribution with $h-K$ degrees of freedom where $K$ is the number of parameters estimated in the model.

Nonnormality of the distribution of residuals of the exchange rate series under the study is confirmed using Jarque-Bera test statistic, Q-Q plot and empirical density graph, supporting the use of generalized error distribution in estimation of volatility models.

Thereafter, GARCH $(1,1)$ has been applied to the time series for symmetric 
volatility estimation and EGARCH $(1,1)$ model has been applied to capture the leverage effect, that is, the existence of asymmetry, if any, in response of the series to positive and negative shocks of the same magnitude. The data window is rolled over five years with nearly 1200 observations and one month is used as forecast period for each window.

\subsection{Volatility Modelling}

Both symmetric and asymmetric GARCH models have been used for estimation of conditional variance of the exchange rate time series under the study. The models used are described below.

\subsubsection{Symmetric GARCH Model}

GARCH, introduced by [2] is a generalization of the ARCH model proposed by [1]. GARCH models today's conditional variance as linear function of yesterday's volatility and past squared innovations in the mean equation. The most basic form of GARCH is the low order GARCH $(1,1)$, which has only one lagged error square term and one autoregressive term. The authors have also used the GARCH $(1,1)$ model for the current study. The return equation of GARCH is represented as:

$$
R_{t}=c+\rho R_{t-1}+\varepsilon_{t}
$$

and the volatility equation as:

$$
\sigma_{t}^{2}=\alpha_{0}+\alpha_{1} \varepsilon_{t-1}^{2}+\cdots+\alpha_{p} \varepsilon_{t-p}^{2}+\beta_{1} \sigma_{t-1}^{2}+\cdots+\beta_{q} \sigma_{t-q}^{2}
$$

where $\alpha_{0}>0, \alpha_{1}, \cdots, \alpha_{p}, \beta_{1}, \cdots, \beta_{q} \geq 0$

The model assumes that innovations or shocks $\left(\varepsilon_{t}\right)$ follow independent and identical distribution with mean equal to 0 and variance equal to 1 . Symbolically,

$$
\varepsilon_{t}=z_{t} \cdot \sqrt{\sigma_{t}^{2}}
$$

where, $z_{t} \sim N(0,1)$ and $\sigma_{t}^{2}$ is represented by:

$$
\sigma_{t}^{2}=\omega+\alpha \varepsilon_{t-1}^{2}+\beta \sigma_{t-1}^{2}
$$

where

$\omega>0, \alpha, \beta \geq 0 \quad$ (since variance should be not be negative)

$\sigma_{t}^{2}=$ conditional volatility

$\varepsilon_{t-1}^{2}=$ actual volatility

$\omega=$ the standard notation for GARCH constant

$\alpha=$ the GARCH error coefficient

$\beta=$ the GARCH lag coefficient

Equation (7) may be rewritten as follows:

$$
\sigma_{t}^{2}=\omega+(\alpha+\beta) \sigma_{t-1}^{2}+\alpha\left(\varepsilon_{t-1}^{2}-\sigma_{t-1}^{2}\right)
$$

where,

$$
\varepsilon_{t-1}^{2}-\sigma_{t-1}^{2}=\text { unexpected volatility }
$$

The average variance based on this model is estimated as: 


$$
\sigma^{2}=\frac{\omega}{1-\alpha-\beta}
$$

The values of $\alpha$ and $\beta$ parameters determine the short-run volatility of the time series being modelled. A high value of $\alpha$ indicates that the volatility responds quite strongly to the market movements. On the other hand, a high $\beta$ indicates reverberation and persistence of shocks to conditional variance. $(1-\alpha-$ $\beta)$ measures dying out volatility. This means $(\alpha+\beta)$ measures persistence of volatility. Therefore, if $(\alpha+\beta)$ is equal to one, volatility does not die out and if $(\alpha+$ $\beta$ ) is greater than one than the volatility explodes or increases the next day. To prevent this, GARCH models impose the condition of $(\alpha+\beta)<1$.

\subsubsection{Asymmetric GARCH Model (EGARCH)}

The EGARCH model, proposed by [40], includes a term for the leverage effect in the estimation equation to accommodate the difference between the impact positive and negative shock of same magnitude. To ensure that conditional variance is positive, the model log-transforms it. The model specification for return and conditional variance is given as:

$$
\begin{gathered}
R_{t}=c+\rho R_{t-1}+\varepsilon_{t} \\
\varepsilon_{t}=Z_{t} \cdot \sqrt{\sigma_{t}^{2}}
\end{gathered}
$$

where, $Z_{t} \sim N(0,1)$ and $\sigma_{t}^{2}$ is represented by:

$$
\ln \left(\sigma_{t}^{2}\right)=\omega+\alpha\left(\left|Z_{t-1}\right|-E\left|Z_{t-1}\right|\right)+\gamma Z_{t-1}+\beta \ln \left(\sigma_{t-1}^{2}\right)
$$

where $Z_{t-1}$ is the standardized residual

$\alpha$ represents the symmetric effect of the model, the "GARCH" effect. $\gamma$ measures the asymmetry or the leverage effect. If $\gamma=0$, then the model is symmetric. When $\gamma<0$, then positive shocks generate less volatility than negative shocks. When $\gamma>0$, it implies that positive innovations are more destabilizing than negative innovations. The total effect of a positive shock of one standardized unit is $(1+\gamma)$, while that of negative shock is $(1-\gamma) . \beta$ is the coefficient of the autoregressive term in Equation (12) and it measures the persistence in conditional volatility, irrespective of the market movement. When $\beta$ is relatively large, then the volatility takes longer time to die out following a crisis in the market (Alexander [41]). Non-negativity of parameters is not imposed in EGARCH due to the exponential specification of this model.

\subsection{Residual Distribution}

Both GARCH and EGARCH have been estimated in the current study assuming GED distribution of residuals. Use of nongaussian distribution is more adequate because many observed series do not exhibit normal distribution. GED accommodates the GARCH residuals that tend to be heavy tailed. The use of GED when estimating EGARCH was proposed by Nelson [40] as it is superior in terms of fulfilling stationarity compared to other distributions. The log-likelihood function used for the estimation of parameters on volatility models for GED is 
given as:

$$
\ln L\left[\left(y_{t}\right), \theta\right]=\sum_{t=1}^{T}\left[\ln \left(\frac{\vartheta}{\pi}\right)-\frac{1}{2}\left|\frac{z_{t}}{\pi}\right|^{\vartheta}-\left(1+\vartheta^{-1}\right) \ln (2)-\ln \tau\left(\frac{1}{\vartheta}\right)-\frac{1}{2} \ln \left(\sigma_{t}^{2}\right)\right]
$$

where, $\pi=\left[2^{\frac{-2}{\vartheta}}\left(\frac{\tau \frac{1}{\vartheta}}{\tau \frac{3}{\vartheta}}\right)\right]^{\frac{1}{2}}$

GED incorporates normal distribution when $\mathcal{\vartheta}=2$, Laplace distribution when $\mathcal{\vartheta}=2$, and unique distribution when $\mathcal{\vartheta}=\infty$.

\subsection{In-sample Model Comparison Criteria}

The scope of this study includes identification of the best fit model and evaluation of forecasting efficacy of the estimated models. The study has applied three penalized-likelihood information criteria, namely, AIC, BIC and HQ for model comparison. The selection criteria used by these models has one goodness-of-fit term and a penalty to control over-fitting. The model with lowest AIC, BIC, or HQ is selected. In addition to these three criteria, log likelihood value is also used to compare the models as GARCH estimation is based on maximum likelihood. The higher the log likelihood value, the better is the model.

\subsubsection{Akaike Information Criterion}

AIC [7] is an asymptotically unbiased estimate of the Kullback-Leibler index [42] of the fitted model relative to the true model. AIC is mathematically specified as:

$$
K(p)=-2 \log \left(\hat{\sigma}_{2}\right)+2 p
$$

where, $\hat{\sigma}_{2}$ is the estimated model error variance

$p$ is the number of parameters in the model $p=0,1,2, \cdots, m$

The first term in Equation (14) rewards the fit between the model and the data, while the second term imposes penalty for over-fitting.

\subsubsection{Bayesian Information Criterion}

The BIC/SIC [8] has been estimated from a Bayesian perspective and it imposes a harsher penalty for over-fitting as compared to AIC. BIC, a more parsimonious model, is mathematically specified as:

$$
\mathrm{BIC}=-2 \log \left(\hat{\sigma}_{2}\right)+p \log (n)
$$

where $\hat{\sigma}_{2}$ is the estimated model error variance $p$ is the number of free parameters in the model $n$ is the number of observations

\subsubsection{Hannan-Quinn Criterion}

HQC [9] is based on the law of iterated logarithm and it allows the penalty function to decrease with the increase in sample size. Mathematically:

$$
\mathrm{HQ}=-\log \left(\hat{\sigma}_{2}\right)+2 p \log (\log (n))
$$


where $\hat{\sigma}_{2}$ is the estimated model error variance

$p$ is the number of parameters in the model

$n$ is the number of observations

\subsection{Evaluation of Out-of-Sample Forecast Accuracy}

The real purpose of specifying volatility models is to forecast future conditional volatility as accurately as possible. The estimated models need to be tested for accuracy of forecasts they. The efficacy of the GARCH-family models is usually evaluated on the basis of their out-of-sample predictions. There are four popular measures, namely, Root Mean Squared Error (RMSE)/Mean Squared Error (MSE), Mean Absolute Error(MAE), Mean Absolute Percentage Error (MAPE) and Theil's Inequality Coefficient (TIC) that are commonly used by researchers to evaluate forecasting efficacy of the estimated models. Reference [43] has discussed and specified these forecast evaluation measures in his work. In the current study, MSE and MAE have been used to evaluate the forecasting efficacy of the models specified.

MSE weighs greater forecast errors more severely in the average forecast error penalty. It is particularly useful when large errors are undesirable. It is based on ' $n$ ' out-of-sample forecasts from $t=t+1, t+2, \cdots, t+n$ and is specified as:

$$
\frac{1}{n} \sum_{t=1}^{n}\left(\sigma_{M t}^{\wedge 2}-\sigma_{M t}^{2 \text { Real }}\right)^{2}
$$

where, ' $n$ ' stands for the number of out-of-sample forecasts, $\sigma_{M t}^{2 \text { Real }}$ represents the actual or realized variance at ' $t$ ' and $\sigma_{M t}^{\wedge 2}$ is the forecasted variance at ' $t$.

MAE is a measure of the average absolute forecast error and it does not permit the offsetting effects of over and under-prediction. It is specified as:

$$
\frac{1}{n} \sum_{t=1}^{n}\left|\sigma_{M t}^{\wedge 2}-\sigma_{M t}^{2 \text { Real }}\right|
$$

Where, ' $n$ ' stands for the number of out-of-sample forecasts, $\sigma_{M t}^{\text {2Real }}$ represents the actual variance at ' $t$ ' and $\sigma_{M t}^{\wedge 2}$ is the forecasted variance at ' $t$ '.

These metrics are calculated for both models and both currency pairs. The values of MSE and MAE can range from zero to infinity. The best model is one that has the lowest values for the error measurement techniques applied for the purpose.

The informational efficiency of both the models has been analyzed on the basis of their out-of-sample performance. A rolling data sample covering a period of five years has been used to arrive at the parameters of each model. Thus the data of daily exchange rate returns for the period from April 1, 2006 through March 31, 2011 is used to estimate the GARCH and EGARCH parameters as on March 31, 2011. These parameters are used to forecast the conditional variance for the first day of the April 2011. Similarly, one-, two-, five- and n-day ahead forecasts are constructed where $\mathrm{n}$ is the number of trading days in the month. The cumulative variance for the month is arrived at by summing up the daily forecasts. The cumulative forecast variance is divided by the number of trading 
days in the month to obtain the forecast monthly variance. Then the data set is rolled forward by a month and the five-year period from May 1, 2006 to April 29, 2011 is used to estimate the parameters for May 2011 and so on. This process is continued till the estimation of variance for the last month in the data sample, i.e. January 2018. Under the GARCH model, the one-day-ahead forecast is arrived at as given in Equation (19).

$$
\sigma_{t+1}^{2}=\omega+\alpha \varepsilon_{t}^{2}+\beta \sigma_{t}^{2}
$$

And the t-day-ahead forecast is arrived at as:

$$
\sigma_{t+T}^{2}=\omega+\alpha \varepsilon_{t+T-1}^{2}+\beta \sigma_{t+T-1}^{2}
$$

Under the EGARCH $(1,1)$ model the one-day-ahead forecast is arrived at as:

$$
\sigma_{t+1}^{2}=\varphi \mathrm{e}^{\left(\omega-\gamma * \sqrt{\frac{2}{\pi}}\right)} \sigma_{t}^{2 \beta}
$$

where $\sigma_{t}^{2}$ is determined according to Equation (12) and

$$
\varphi=\mathrm{e}^{\left(\frac{\theta+\gamma^{2}}{2}\right)} N(\theta+\gamma)+\mathrm{e}^{\left(\frac{(\gamma-\theta)^{2}}{2}\right)} N(\gamma-\theta)
$$

In which $N()$ stands for standard normal distribution.

The monthly variance $\sigma_{M}^{\wedge 2}$, is determined according to Equation (23) in which $\sigma_{D_{t+i}}^{\wedge 2}$ represents the daily ex-ante forecast of conditional variance for the $I^{\text {th }}$ day of the month estimated at time $t$ under the $\operatorname{GARCH}(1,1)$ and $\operatorname{EGARCH}(1,1)$ models and $n$ is the number of trading days in the month.

$$
\sigma_{M}^{\wedge 2}=\frac{1}{n} \sum_{i=1}^{n} \sigma_{D_{t+i}}^{\wedge 2}
$$

The forecast monthly variances under each model are then compared with the realized variance for the month. The realized variance is arrived at as per Equation (24), specified as follows:

$$
\sigma_{M}^{2 \text { Real }}=\frac{1}{n} \sum_{i=1}^{n} r_{t+i}^{\wedge 2}
$$

where $\sigma_{M}^{2 \text { Real }}$ is the realized variance for the month, $r_{t+i}^{\wedge 2}$ is the squared return for day $i$ calculated ex-post and $n$ is the number of trading days in the month.

\subsection{Robustness Test}

In order to test the robustness of the results out-of-sample forecasts are also constructed for two different periods under each of the models-a period of depreciation and a period of appreciation in the rupee. The period of depreciation of the rupee against both dollar and euro is taken as May 24, 2013 to September 5,2013 . This period corresponds with the Taper tantrum crisis which affected all emerging markets as a result of the announcement of the decision of the US Federal Reserve to gradually wind down its program of quantitative easing. The rupee witnessed a very high level of volatility against both USD and EUR during this period, falling nearly 19 per cent and 21 per cent against the dollar and the euro respectively. Hence, this period is considered most appropriate to judge the 
forecasting ability of both models against the backdrop of severe volatility pressures.

Further, a model that performs well during a volatile period may not necessarily perform as well during a tranquil period. Therefore, out-of-sample performance is also examined during periods of strengthening rupee-November 25, 2016 to March 30, 2017 for the USDINR and August 26, 2016 to December 27, 2016 for the EURINR. During these periods, the rupee appreciated by nearly 5 per cent and 6 per cent against the dollar and euro respectively. The movement of both the exchange rate series under the study is exhibited in Figure 1. Out-of-sample forecasts are constructed for each week during the volatile and tranquil periods again on the basis of a rolling five-year data sample. The sample is rolled forward every week for estimating the model parameters for the next week. Weekly forecast variances are compared with the realized weekly variances and the error metrics, MSE and MAE are computed as explained earlier.

\subsection{Test of Superior Predictive Accuracy}

The Diebold-Mariano [14] test (DM test), is used to compare the predictive accuracy of both models over the entire sample period. DM test rests on assumptions made directly on the forecast error loss differential. Both loss functions, i.e. squared and absolute are considered. Further, the test does not make any assumptions about the distribution of the forecast errors and incorporates both, the temporal autocorrelations as well as correlation between the given series. The null hypothesis of the DM test is that both methods have equal forecast accuracy.

The loss associated with forecast $\mathrm{I}$ is assumed by the test to be a function of the forecast error $\left(e_{i t}\right)$, and is denoted by $g\left(e_{i t}\right)$. Here, $g\left(e_{t t}\right)$ is the square (squared-error loss) or the absolute value (absolute error loss) of $e_{i t}$ The test statistic of DM test is specified as:

$$
\frac{\bar{d}}{\sqrt{\widehat{\operatorname{avar}(\bar{d})}}}=\frac{\bar{d}}{\sqrt{\widehat{L R V}_{\bar{d}} / T}}
$$

where

$$
\bar{d}=\frac{1}{T_{0}} \sum_{t=t_{0}}^{T} d_{t}
$$

$T_{0}$ is number of forecasts

$d_{t}$ is loss differential

$\widehat{L R V}_{\bar{d}}$ is a consistent estimate of the asymptotic variance of $\sqrt{T} \bar{d}$

The null hypothesis of no difference is rejected if the DM test statistic falls outside the range of -1.96 to 1.96 .

The DM test and its modifications thereof, have been used by researchers quite extensively in the context of testing the efficacy of economic forecasting. Many studies have used this test to assess the superior predictive ability of forecasting methods [44] [45] [46] and [47]. 

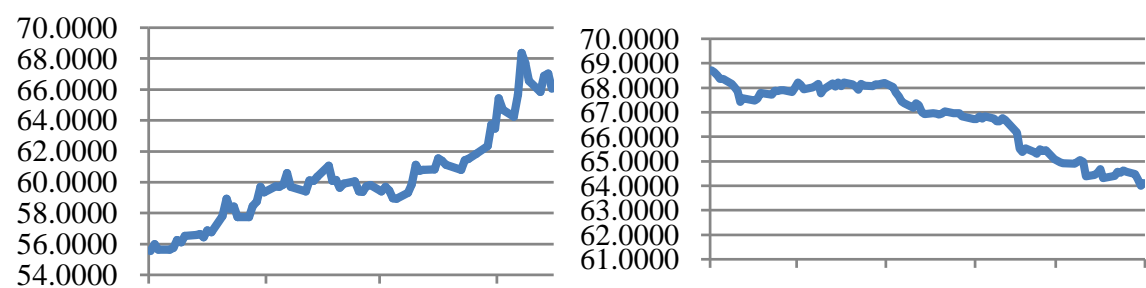

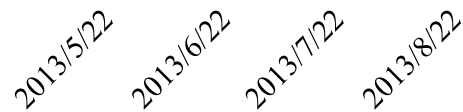

(a)
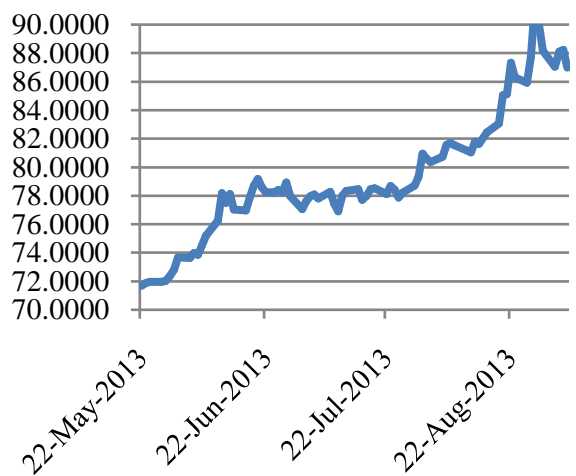

(c)

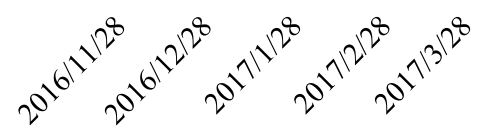

(b)

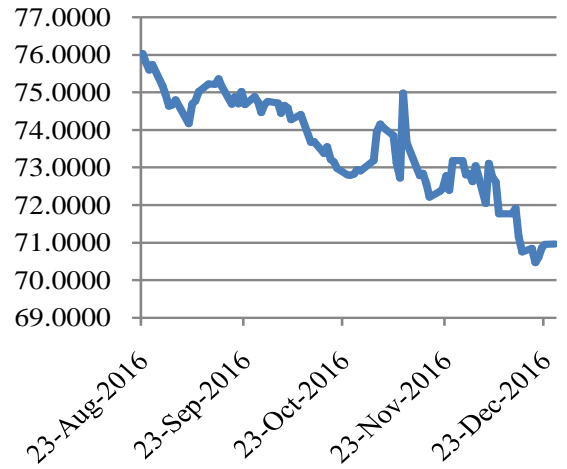

(d)

Figure 1. Periods of depreciation and appreciation in the rupee. (a) Volatile period for USDINR; (b) calm period for USDINR; (c) volatile period for EURINR; (d) calm period for EURINR. Source: Authors' computations.

\section{Data Description}

Data duration, frequency, descriptive statistics, stationarity characteristics, volatility clustering and the existence of $\mathrm{ARCH}$ effect in relation to the data under the study is discussed in this section.

\subsection{Data}

The time series data for rupee exchange rate against USD and EUR are used for modelling volatility of INR in the current study. The daily rupee exchange rate against US Dollar and the euro for a period spanning April 1, 2006 through January 31, 2018 has been used to model volatility of INR, resulting in total observations of 2861. The data series under the study have been extracted from the Reserve Bank of India online database.

The time-varying volatility models, such as the ones used in the current study, are very sensitive to data frequency. Using low frequency data for GARCH-type models will not yield any meaningful results as it might fail to capture volatility clustering and persistence. Volatility clustering and non-Gaussian behavior in financial returns is typically seen in weekly, daily or intraday data. Thus, daily data has been chosen for the study. Even daily data may not capture the volatility occurring during the trading day but the authors has chosen to use it as there are practical problems related to the availability and management of intra-day data. 
Daily data suffices the purposes of the study as it can be expected to produce better forecasts of weekly and monthly volatility than GARCH models fitted to weekly or monthly returns, as shown in a study by [48].

GARCH models are also sensitive to data duration, that is, how far the data goes in the past and the volatility during the period under the study. The period of April, 2006 through January, 2018 has been chosen to offer enough economic variations to draw meaningful inferences. This data duration has also been chosen to have sufficient number of observations to ensure stability of parameter estimates as the data window is rolled forward to assess the forecasting ability of the model over time. In the current study, window is rolled across approximately 1200 observations. The size of the rolling window is dependent on data frequency and periodicity. It is common to use a short rolling window for short data duration and a long window for data of longer duration. The longer the rolling window, the smoother the estimates. Based on previous forecasting applications of the GARCH models, a rolling window of $\mathrm{N}=2000$ is most commonly used [44] [49] [50] and [51]. Since we are using medium-sized data duration for the current study, the chosen rolling window length is less than 2000 .

\subsection{Descriptive Statistics}

Descriptive statistics of the return data of the two series are important to understand the nature of the data under the study. From the summary statistics given in Table 1, certain inferences about the behavior and distribution pattern of the time series under the study have been drawn.

It can be seen in Table 1 that the USD and EUR return series have skewness equal to 0.209689 and 0.001503 and kurtosis of 8.1246 and 6.261392 respectively. Under normal distribution, skewness is zero and kurtosis is 3. Positive skewness and higher kurtosis indicate that both return series are asymmetrically skewed towards right and peaked. Excess kurtosis for both series confirms that they follow leptokurtic distribution with large fluctuations more likely to occur within the fat tails. The JB test statistic rejects the null hypothesis of zero skewness and excess kurtosis at $5 \%$ level, confirming departure from normality.

Non-normality of distribution is also visually confirmed by Q-Q plot, given in Figure 2, which displays the quantiles of return series against the quantiles of the normal distribution. The plot confirms that there is a low degree of fit of the empirical distribution to the normal distribution for both the series.

The leptokurtic behavior of the series under the study is also confirmed by the normal quintile and empirical density graph presented in Figure 3 for both the series under the study.

Table 1. Summary statistics of the daily returns of USDINR and EURINR.

\begin{tabular}{ccccccccc}
\hline Series & $\mathrm{N}$ & Mean & Std. Dev. & Variance & Skewness & Kurtosis & Jarque-Bera & Probability \\
\hline RUSD & 2860 & 0.0124 & 0.4995 & 0.2495 & 0.2096 & 8.1246 & 3150.457 & 0 \\
REURO & 2860 & 0.0001 & 0.0065 & 0.000042 & 0.0015 & 6.2613 & 1267.539 & 0 \\
\hline
\end{tabular}

Source: Authors' computations. 
RUSDINR

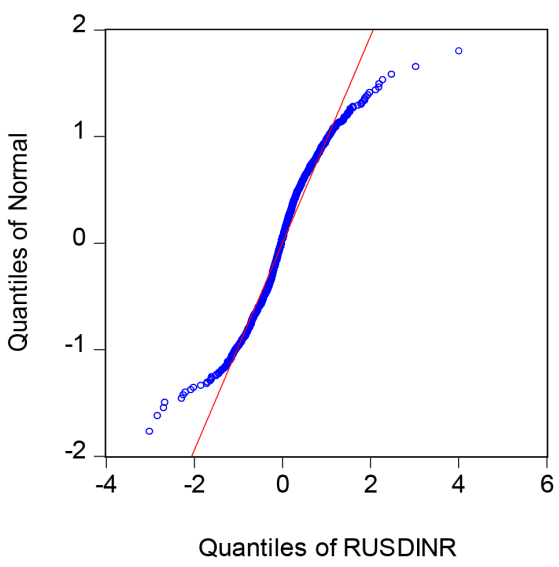

(a)
REUROINR

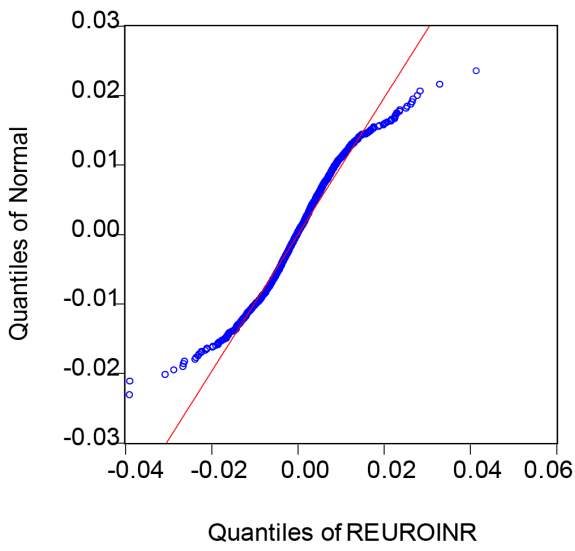

(b)

Figure 2. Q-Q plot of daily returns of the INR exchange rate series. Source: Authors' computations.

\section{RUSDINR}

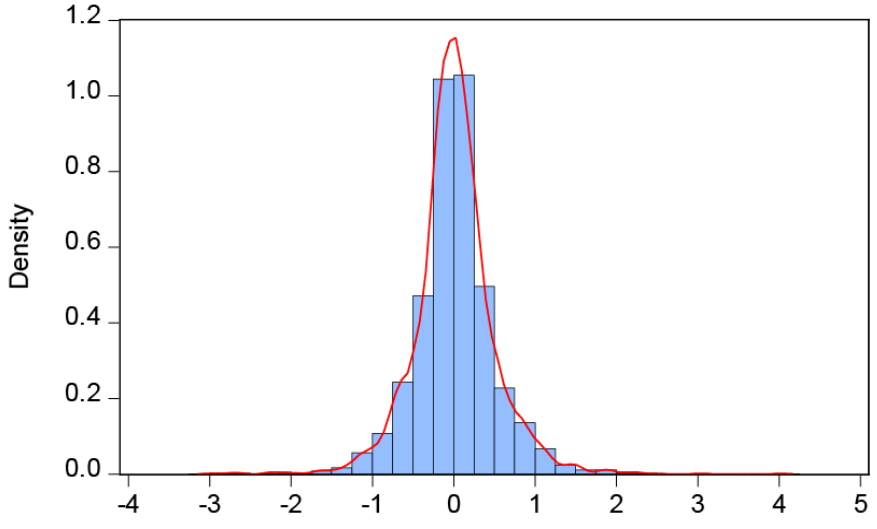

REUROINR

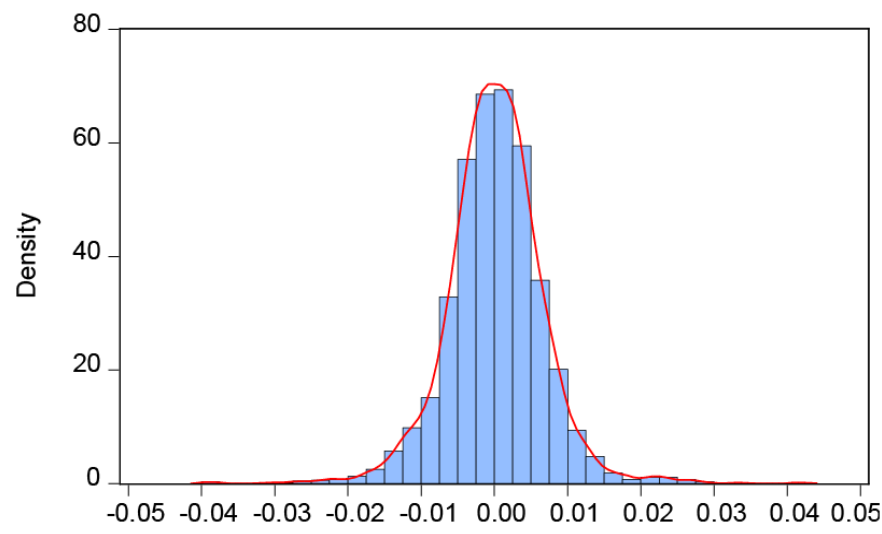

Histogram - Kernel

Figure 3. Normal density graphs of daily returns of the INR exchange rate series. Source: Authors' computations. 


\subsection{Unit Root Tests}

Since the exchange rates represent financial time series, they may suffer from the problem of non-stationarity. Regressing such series may result into a spurious regression that is meaningless in its implication. Therefore, the series under the study have been tested for stationarity before modelling volatility using ADF and PP tests described in the section on methodology. The results of the ADF and PP unit root tests, tabulated in Table 2, show that the exchange rate series follow I (1) process i.e. non-stationary at levels but stationary at first difference.

Thus, for applying the GARCH models, the closing rupee values have not been used directly. They have been converted into log-transformed (first differenced) series by using the formula given below.

$$
R_{t}=L N\left(\frac{E_{t}}{E_{t-1}}\right) * 100
$$

where $R_{t}$ is the daily percentage return to the exchange rate and $E_{t}$ and $E_{t-1}$ denote the exchange rate at the end of the current day and previous day, respectively.

Non-stationarity at levels and stationarity at first difference can also be confirmed visibly through examining the time series plots for the two series illustrated in Figure 4.

\subsection{Volatility Clustering}

The GARCH-family models can be used only for data that exhibits volatility clustering, which is confirmed in this study through plot of residuals of the two series. It is given in Figure 5.

\subsection{ARCH Effect}

As discussed in the section on methodology, the existence of serial correlation among residuals is a necessary prerequisite for applying GARCH models. ARCH

Table 2. ADF and PP unit root test for stationarity in the INR exchange rate series.

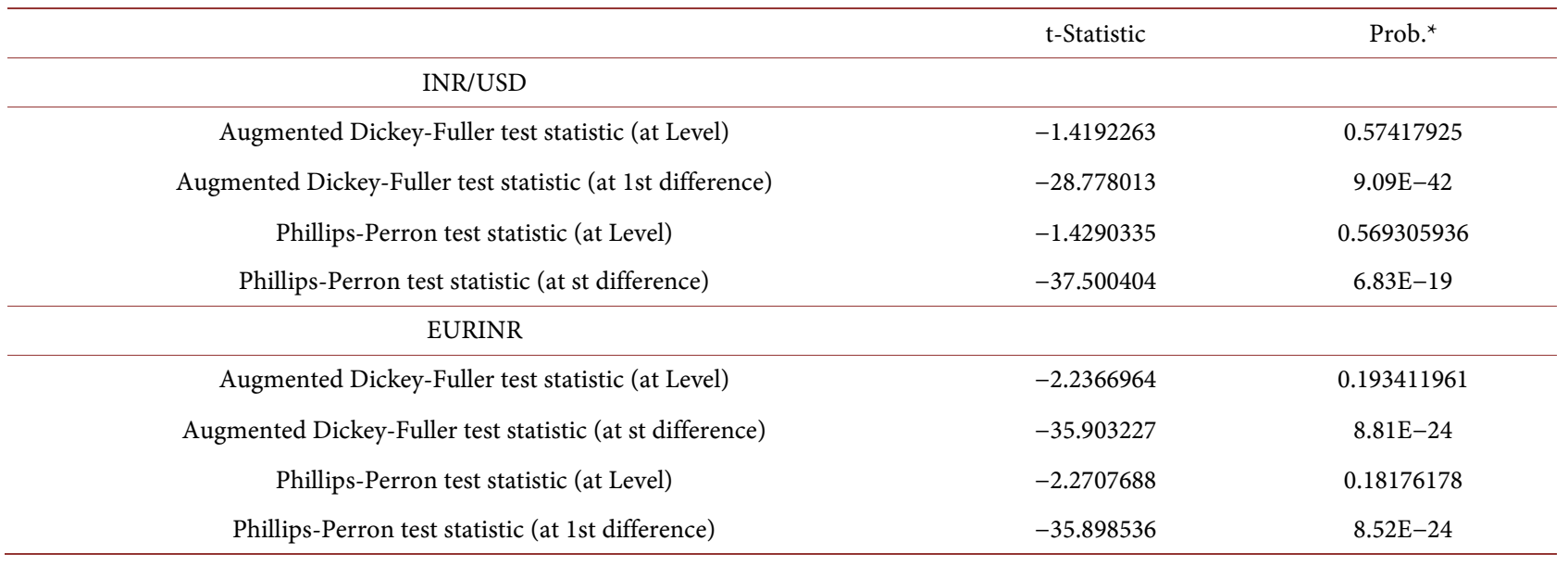

${ }^{\star}$ MacKinnon (1996) one-sided p-values. Source: Authors' computations. 
USD

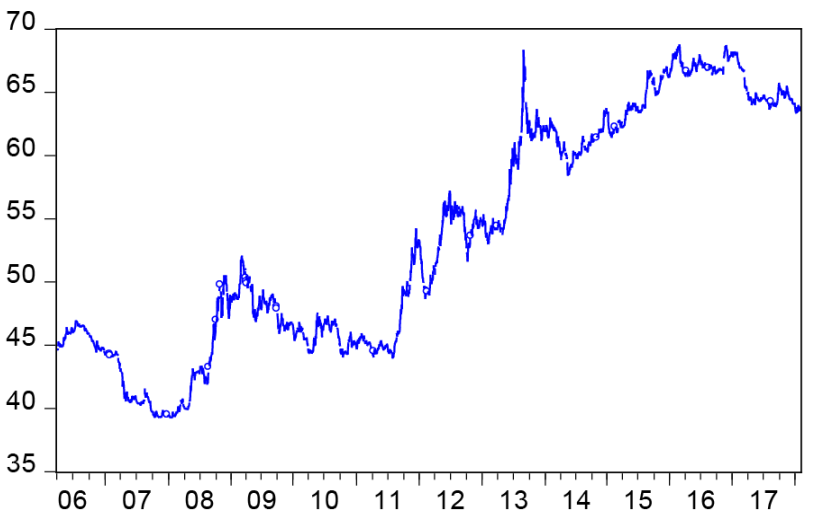

(a)

RUSDINR

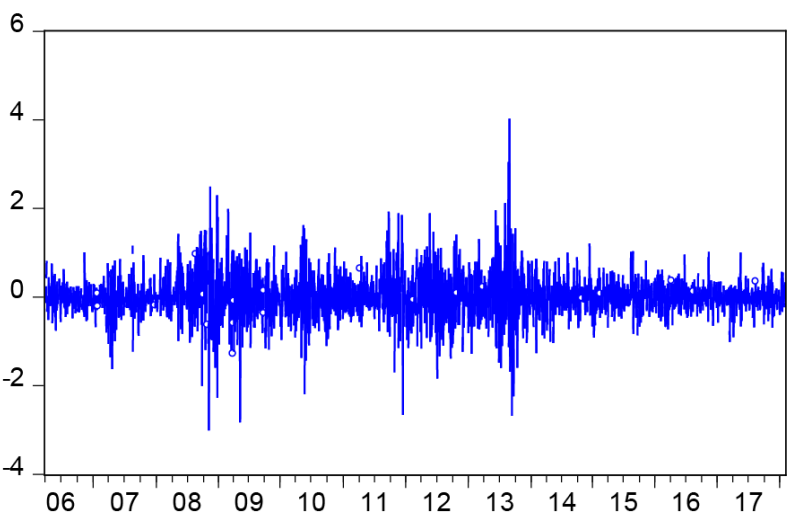

(c)
EURO

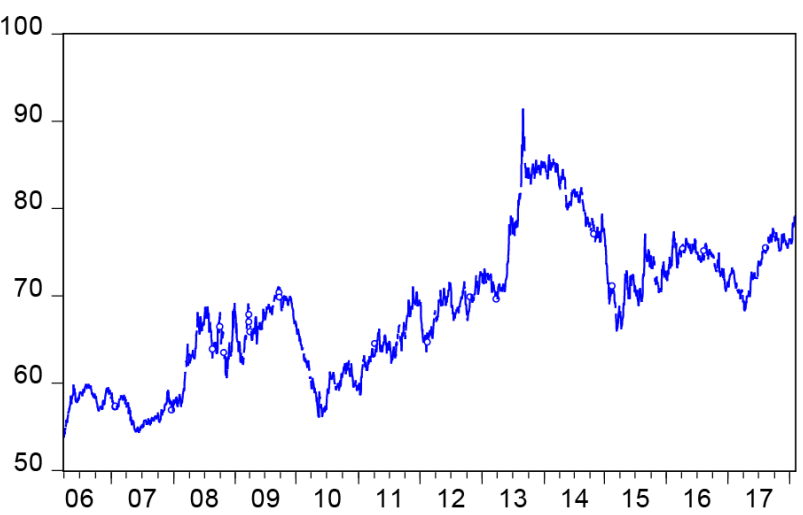

(b)

REUROINR

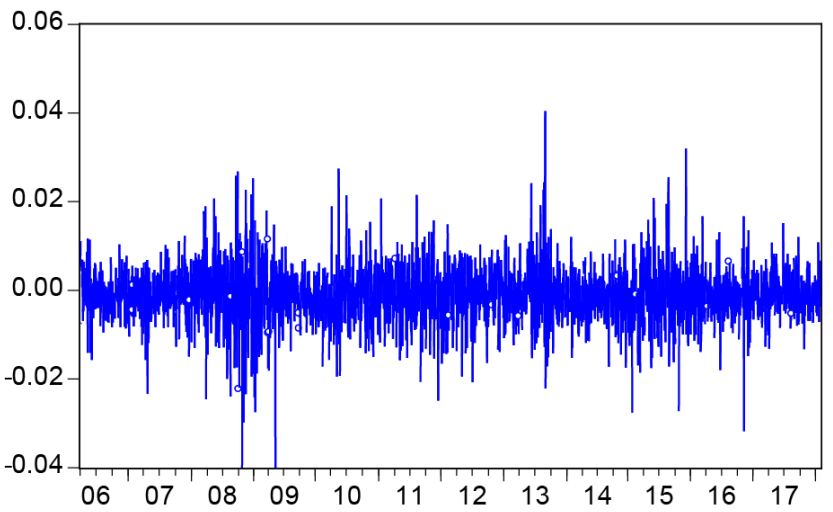

(d)

Figure 4. Plot of USDINR and EURINR at levels and first difference. Source: Authors' computations.

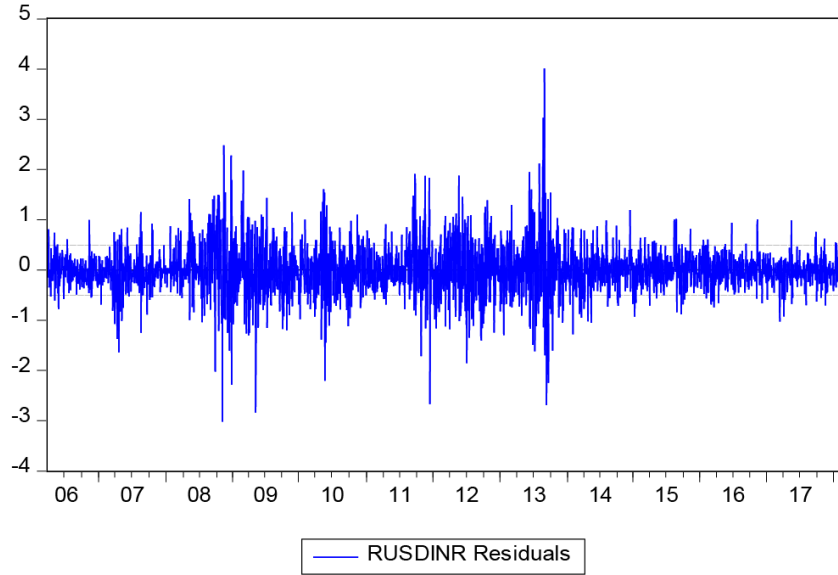

(a)

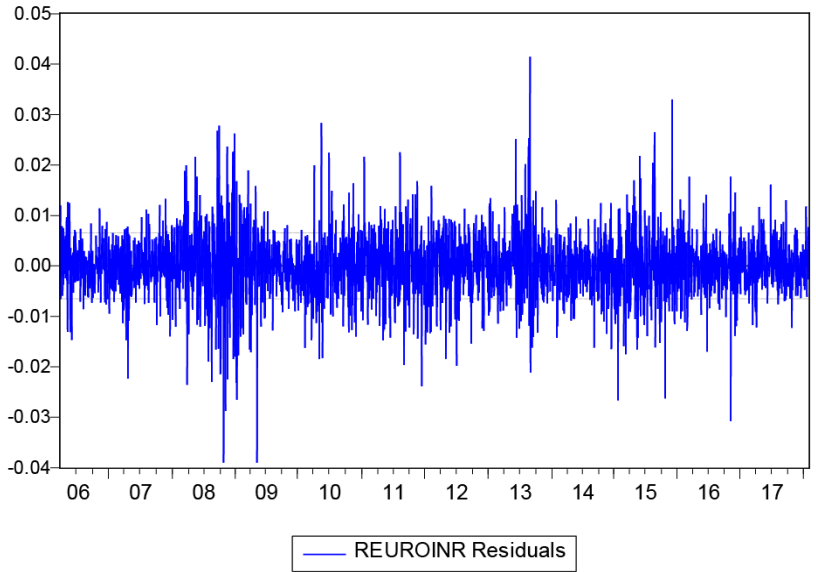

(b)

Figure 5. Evidence of volatility clustering in the INR exchange rate series. Source: Authors' computations.

LM (Lagrange multiplier) test is applied to the first differenced series of the two exchange rate series under the study to verify the existence of the ARCH effect. 
The test statistic (obs ${ }^{\star} \mathrm{R}$-squared) is 140.9605 and the probability Chi-Square (1) is 0.0 for USDINR and the test statistic (obs ${ }^{\star} \mathrm{R}$-squared) is 78.65950 and the probability Chi-Square (1) is 0.0 for EURINR. On the basis of high value of $\mathrm{obs}^{\star} \mathrm{R}$-squared and low probability, the null hypothesis of no ARCH effect is rejected. Thus, the existence of ARCH effect is confirmed.

Ljung Box Q-statistics for 1st to 15th lags of the sample autocorrelations functions are statistically significant for both the series, as seen in Figure 6, thereby reconfirming the existence of the ARCH effect.

Thus, GARCH-family models can be applied to the data under consideration.

\section{Analysis of Empirical Results}

The Table 3 and Table 4 show the Maximum Likelihood estimates of the parameters of the two models for the entire sample period from April 2011 to January 2018, assuming that the conditional distribution of the error term follows the Generalized Error Distribution. The parameters are displayed only for ten of the 83 months for the sake of conserving space. Full results are available with the authors on request. Most of the parameter estimates of the GARCH $(1,1)$ and EGARCH $(1,1)$ models are statistically significant at a $5 \%$ level.

As discussed in the section on methodology, a high value of $\alpha$ indicates that the time series responds quite strongly to the market movements and exhibits volatility. The a coefficients computed for $\operatorname{GARCH}(1,1)$ for USDINR from March 2011 to January 2018 indicate that in the recent past the response to market movements has been weakening as compared to the preceding periods as shown in Figure 7.

As mentioned before, a high $\beta$ value indicates persistence of shocks to conditional variance and $(\alpha+\beta)$ measure the persistence of volatility. As is evident from Figure 7, in the recent past, persistence of shocks to conditional variance has been weakening as compared to the preceding periods for USDINR. $(\alpha+\beta)$ value for GARCH $(1,1)$ model was 0.9963 in March 2011 and it came down to 0.9733 in January 2018. A fall in measure of persistence of volatility indicates that the volatility is dying out faster (as measured by $(1-\alpha-\beta)) .(\alpha+\beta)$ remain

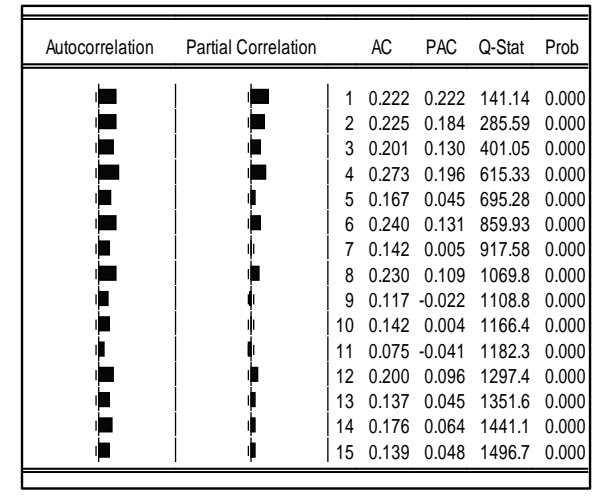

(a)

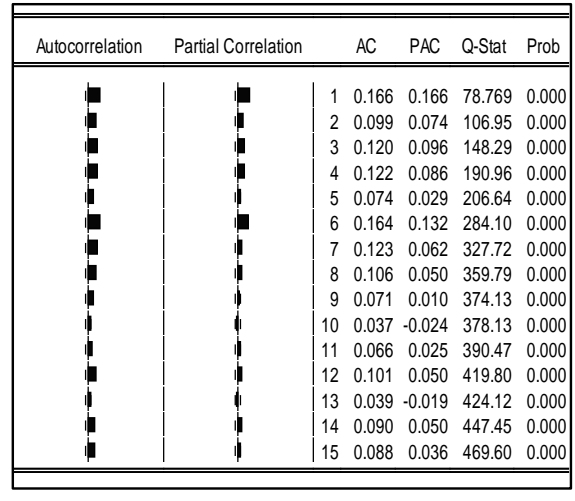

(b)

Figure 6. Q-statistics of the exchange rate series. Source: Authors' computations. 
$\alpha$-USDINR

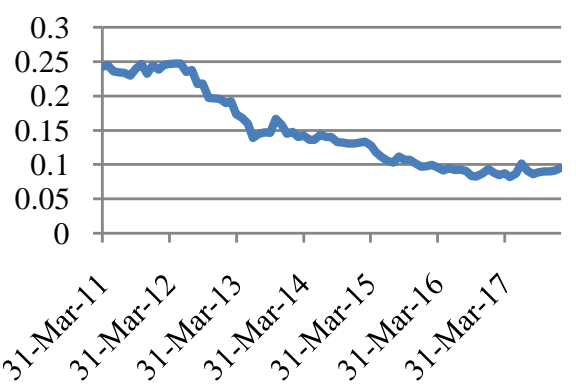

(a)
及-USDINR

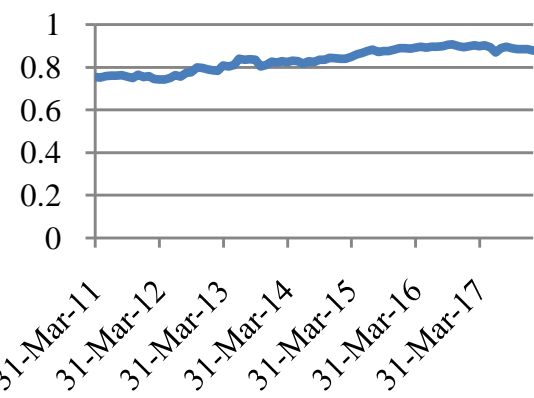

(b)

Figure 7. Behavior of ARCH and GARCH coefficients for USDINR (March 2011-January 2018). Source: Authors' computations.

Table 3. Coefficients for the GARCH $(1,1)$ and $\operatorname{EGARCH}(1,1)$ models for USDINR for the sample period.

\begin{tabular}{cccccccccc}
\hline \multicolumn{7}{c}{ Model coefficients } \\
\hline $\begin{array}{c}\text { Estimation } \\
\text { Date }\end{array}$ & $\omega$ & $\alpha$ & $\beta$ & $\begin{array}{c}\text { GED } \\
\text { parameter }\end{array}$ & $\omega$ & $\alpha$ & $\gamma$ & $\beta$ & $\begin{array}{c}\text { GED } \\
\text { parameter }\end{array}$ \\
\hline 31-Mar-11 & 0.0000 & 0.2428 & 0.7535 & 1.4176 & -0.9632 & 0.4243 & 0.0391 & 0.9412 & 1.3932 \\
28-Apr-17 & 0.0000 & 0.0821 & 0.9027 & 1.4213 & -0.2408 & 0.1329 & 0.0485 & 0.9875 & 1.4158 \\
31-May-17 & 0.0000 & 0.0869 & 0.8954 & 1.3893 & -0.2704 & 0.1467 & 0.0492 & 0.9857 & 1.3847 \\
30-Jun-17 & 0.0000 & 0.1019 & 0.8696 & 1.3859 & -0.3569 & 0.1659 & 0.0542 & 0.9793 & 1.3783 \\
31-Jul-17 & 0.0000 & 0.0907 & 0.8905 & 1.3715 & -0.2743 & 0.1530 & 0.0478 & 0.9859 & 1.3623 \\
31-Aug-17 & 0.0000 & 0.0860 & 0.8957 & 1.3528 & -0.2642 & 0.1426 & 0.0465 & 0.9861 & 1.3424 \\
29-Sep-17 & 0.0000 & 0.0889 & 0.8892 & 1.3460 & -0.2953 & 0.1334 & 0.0623 & 0.9827 & 1.3412 \\
31-Oct-17 & 0.0000 & 0.0901 & 0.8860 & 1.3492 & -0.2827 & 0.1289 & 0.0616 & 0.9836 & 1.3427 \\
30-Nov-17 & 0.0000 & 0.0904 & 0.8856 & 1.3484 & -0.2830 & 0.1302 & 0.0627 & 0.9837 & 1.3410 \\
29-Dec-17 & 0.0000 & 0.0913 & 0.8852 & 1.3427 & -0.2899 & 0.1347 & 0.0659 & 0.9835 & 1.3361 \\
\hline
\end{tabular}

Source: Authors' computations.

close to one throughout the sample period, indicating a stronger presence of ARCH and GARCH effect. This implies that current volatility of daily returns of the two series can be explained by past volatility that tends to persist over time.

A review of the coefficients of $\operatorname{EGARCH}(1,1)$ model for USDINR shows that the size effect of shock coefficient, $\alpha$, has decreased from 0.4243 in March 2011 to 0.1341 in January 2018 indicating declining impact of the magnitude of shock on USDINR volatility. The sign or the leverage effect is represented by the coefficient $\gamma$. As mentioned in the preceding section on methodology, when $\gamma<0$ i.e. negative, then good news generate less volatility than bad news and when $\gamma$ is positive, it implies that positive shocks are more destabilizing than negative news. As seen in Table 3, $\gamma$ is positive for USDINR, indicating positive shocks are more destabilizing. $\beta$ measures the persistence in conditional volatility and its 
Table 4. Coefficients for the GARCH $(1,1)$ and EGARCH $(1,1)$ models for EURINR for the sample period.

\begin{tabular}{cccccccccc}
\hline \multicolumn{7}{c}{ Model coefficients } \\
\hline $\begin{array}{c}\text { Estimation } \\
\text { Date }\end{array}$ & $\omega$ & $\alpha$ & $\beta$ & $\begin{array}{c}\text { GED } \\
\text { parameter }\end{array}$ & $\omega$ & $\alpha$ & $\gamma$ & $\beta$ & $\begin{array}{c}\text { GED } \\
\text { parameter }\end{array}$ \\
\hline 31-Mar-11 & 0.0000 & 0.0539 & 0.9366 & 1.4432 & -0.2089 & 0.1273 & 0.0125 & 0.9891 & 1.4470 \\
28-Apr-17 & 0.0000 & 0.0895 & 0.8510 & 1.4297 & -0.6895 & 0.1711 & 0.0421 & 0.9453 & 1.4311 \\
31-May-17 & 0.0000 & 0.0939 & 0.8425 & 1.4334 & -0.7152 & 0.1780 & 0.0379 & 0.9434 & 1.4338 \\
30-Jun-17 & 0.0000 & 0.1015 & 0.8251 & 1.4064 & -0.8434 & 0.1885 & 0.0413 & 0.9317 & 1.4016 \\
31-Jul-17 & 0.0000 & 0.0843 & 0.8632 & 1.4040 & -0.7053 & 0.1686 & 0.0361 & 0.9436 & 1.3960 \\
31-Aug-17 & 0.0000 & 0.0881 & 0.8551 & 1.4282 & -0.6672 & 0.1671 & 0.0378 & 0.9473 & 1.4210 \\
29-Sep-17 & 0.0000 & 0.0828 & 0.8663 & 1.4209 & -0.6051 & 0.1598 & 0.0345 & 0.9528 & 1.4128 \\
31-Oct-17 & 0.0000 & 0.0832 & 0.8661 & 1.4057 & -0.6177 & 0.1622 & 0.0360 & 0.9518 & 1.3982 \\
30-Nov-17 & 0.0000 & 0.0787 & 0.8756 & 1.4050 & -0.5740 & 0.1576 & 0.0342 & 0.9558 & 1.3974 \\
29-Dec-17 & 0.0000 & 0.0778 & 0.8822 & 1.3975 & -0.5364 & 0.1589 & 0.0342 & 0.9596 & 1.3908 \\
\hline
\end{tabular}

Source: Authors' computations.

large value indicates that volatility takes longer time to die out. For USDINR, $\beta$ has increased from 0.9412 to 0.9817 during the sample period, indicating increasing persistence.

The $\alpha$ coefficients computed for $\operatorname{GARCH}(1,1)$ for EURINR from March 2011 to January 2018 indicate that in the recent past the response to market movements has been weakening as compared to the preceding periods as shown in Figure 8 .

As is evident from Figure 8, in the recent past persistence of shocks to conditional variance has also been weakening as compared to the preceding periods. $(\alpha+\beta)$ value for GARCH $(1,1)$ model was 0.9905 in March 2011 and it came down to 0.9615 in January 2018.

In case of the coefficients of EGARCH $(1,1)$ model for EURINR, $\alpha$ has increased from 0.1273 in March 2011 to 0.1536 in January 2018, indicating rising impact of the magnitude of shock on EURINR volatility. The sign or the leverage effect is represented by the coefficient $\gamma$. As seen in Table $4, \gamma$ is positive for EURINR as well, indicating positive shocks are more destabilizing. For EURINR, $\beta$ has decreased from 0.9891 to 0.9619 during the sample period, indicating decreasing persistence.

In-the-sample model fit criteria is assessed for all 332 models estimated for the two series. The LL, AIC, SIC and HQ criteria have largely indicated $\operatorname{GARCH}(1,1)$ to be the model with better fit for the two series during the period from March 2011 to January 2018. Highest LL and lowest AIC, SIC and HQ values have been used as the decision criteria. Residuals of each of the models estimated in the study have been tested for the absence of ARCH effect and confirmed it. For 
$\alpha-E U R I N R$
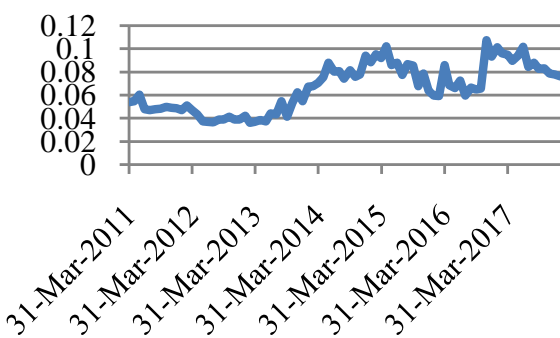

(a)
$\beta$-EURINR
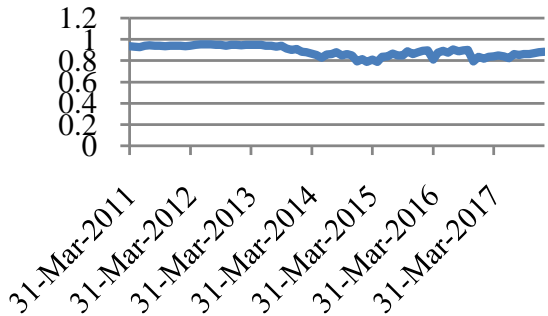

(b)

Figure 8. Behavior of ARCH and GARCH coefficients for EURINR (March 2011-January 2018). Source: Authors' computations.

both the series, the Q statistics on the standard residuals are not significant at the five percent level. Further, in conformance with the GED used for GARCH estimation, the residuals are found to be non-normally distributed, as confirmed by the large JB statistic and its statistical significance. All the related values are reported for the most recent five year data in Table 5.

However, a model with a good in-sample performance may not necessarily perform as well when tested out of sample. Hence, the authors have tested the out-of-sample forecasting efficacy of the estimated models using MSE and MAE.

Results of the out-of-sample test for the entire sample period for the two currency pairs are shown in Table 6. The forecast of the GARCH $(1,1)$ model is seen to result in lower MSE for both currency pairs. However, the MAE of the EGARCH $(1,1)$ model is seen to be lower in case of the USDINR pair.

Although the $\operatorname{GARCH}(1,1)$ model appears to be superior to the $\operatorname{EGARCH}(1,1)$ model on the grounds of lower MSE for both currency pairs and lower MAE for EURINR, the statistical significance of this apparent outperformance needs to be examined. In other words, it needs to be ascertained whether the better forecast accuracy of the GARCH $(1,1)$ model is merely due to chance.

The Diebold-Mariano [14] test is used to compare the predictive accuracy of both methods. For this purpose, the one-day-ahead forecast errors of each model are ascertained by taking the difference between the forecast conditional variance of the model and the actual realized variance over one day. These are then compared using the DM test. Both loss functions, i.e. squared and absolute are considered. Results of the test for both currency pairs are depicted in Table 7.

According to the results of the test, the null hypothesis of equal forecast accuracy cannot be rejected in the case of the USDINR regardless of the loss function used. Hence, the GARCH $(1,1)$ and the $\operatorname{EGARCH}(1,1)$ appear to perform equally well in the context of the USDINR. In the case of the EURINR, the test rejects the null hypothesis when the absolute loss function is considered, implying that both methods do not have equal forecast accuracy. Hence, the null hypothesis is tested against the one-tailed alternative hypothesis that the forecast accuracy of the EGARCH $(1,1)$ model is greater than that of the $\operatorname{GARCH}(1,1)$ model. The 
Table 5. Testing of $\operatorname{GARCH}(1,1)$ and $\operatorname{EGARCH}(1,1)$ using model fit criteria.

\begin{tabular}{ccccc}
\hline Jan 13-Dec 17 & \multicolumn{2}{c}{ USDINR } & \multicolumn{2}{c}{ EURINR } \\
\hline GARCH & EGARCH & GARCH & EGARCH \\
\hline AIC & -57.6639 & -458.5444 & 4494.92 & 4493.396 \\
SIC & 0.771867 & 0.772007 & -7.453356 & -7.454146 \\
HQ & 0.797249 & 0.79962 & -7.427974 & -7.424533 \\
Q(10) & 0.781427 & 0.78116 & -7.443796 & -7.442993 \\
p-value & 10.966 & 10.774 & 14.567 & 14.143 \\
Q(30) & 0.36 & 0.375 & 0.149 & 0.167 \\
p-value & 18.445 & 18.08 & 35.574 & 34.612 \\
JB & 0.951 & 0.957 & 0.222 & 0.257 \\
p-value & 116.23 & 1158.66 & 500.06 & 569.24 \\
F-statistic & 0 & 0 & 0 & 0 \\
p-value & 1.286245 & 1.79312 & 1.282526 & 1.028032 \\
\hline
\end{tabular}

The highest log likelihood (LL) values and the lowest AIC, BIC/SIC and HQ are used to evaluate model fit. Negative values of AIC, SIC and HQ indicate less information loss than positive ones and therefore indicate a better model fit. Source: Authors' computations.

Table 6. Results of the out-of-sample test for the sample period for the two currency pairs.

\begin{tabular}{ccccc}
\hline & \multicolumn{2}{c}{ USDINR } & \multicolumn{2}{c}{ EURINR } \\
\cline { 2 - 5 } & GARCH $(1,1)$ & EGARCH $(1,1)$ & GARCH $(1,1)$ & EGARCH $(1,1)$ \\
\hline MSE & 0.00006 & 0.00009 & 0.00006 & 0.00009 \\
MAE & 0.00614 & 0.00522 & 0.00525 & 0.00584 \\
\hline
\end{tabular}

Source: Authors' computations.

Table 7. Results of the Diebold-Mariano test-entire sample.

\begin{tabular}{ccccc}
\hline & \multicolumn{2}{c}{ USDINR } & \multicolumn{2}{c}{ EURINR } \\
\hline \multicolumn{4}{c}{ Alternative hypothesis : (Two-tailed) } \\
\hline Loss function & DM-statistic & P-value & DM-statistic & P-value \\
\hline Squared loss function & -0.8566 & 0.3942 & 0.1967 & 0.8446 \\
Absolute loss function & -0.1535 & 0.8784 & 3.2474 & 0.0017 \\
\hline Alternative hypothesis: & Forecast accuracy of EGARCH(1,1) is greater & \\
\hline & & & 3.2474 & 0.0008 \\
\hline
\end{tabular}

Source: Authors' computations.

p-value (0.0008) is statistically significant indicating that the null of equal accuracy may be rejected in favour of the alternative hypothesis that the EGARCH $(1,1)$ has greater forecast accuracy than the GARCH $(1,1)$ model in the context of the EURINR. 
The above results are for the entire sample period and could obscure the true performance of the two models. A month-by-month comparison of the squared errors and absolute errors of the two models reveals that the EGARCH $(1,1)$ model actually results in lower MAE and MSE than the GARCH $(1,1)$ model in 58 out of 82 months for the USDINR pair and 37 out of 82 months for the EURINR pair. Hence, the robustness of these results is verified by examining the performance of the models over a volatile and a calm period. Results are documented in Table 8.

The results show that the GARCH $(1,1)$ clearly scores better than the EGARCH $(1,1)$ model on the MSE criterion. It exhibits a lower MSE than the EGARCH $(1,1)$ during the volatile period in respect of both the currency pairs. During the period of rupee appreciation, the $\operatorname{GARCH}(1,1)$ results in a lower MSE than the EGARCH $(1,1)$ in case of the USDINR while the MSE of both models is almost comparable in the case of the EURINR. However, the superior performance of the GARCH $(1,1)$ model is slightly dented when the MAE criterion is considered. The EGARCH $(1,1)$ model is observed to exhibit a lower MAE than the GARCH $(1,1)$ model during both periods in respect of EURINR. However, the MAE of the GARCH $(1,1)$ model is consistently lower than that of the EGARCH $(1,1)$ in respect of the USDINR during both the periods.

Table 9 shows the model with the lower MSE/MAE during each of the periods for both currency pairs. On the whole, the GARCH $(1,1)$ model appears to perform better than the EGARCH $(1,1)$ model on the basis of the MSE loss function as it exhibits a lower MSE than the latter in a majority of the currency-time period buckets. The performance of the two models is equally divided when the MAE criterion is considered.

\section{Summary and Conclusion}

Fluctuations in exchange rates impact the profits of various groups such as importers, exporters, investors, traders and have bearing on the decisions taken by

Table 8. Robustness test over a volatile and a calm period.

\begin{tabular}{|c|c|c|c|c|}
\hline \multicolumn{5}{|c|}{ Panel A: Performance during volatile period } \\
\hline & \multicolumn{2}{|c|}{ USDINR } & \multicolumn{2}{|c|}{ EURINR } \\
\hline & GARCH $(1,1)$ & EGARCH( $(1,1)$ & GARCH $(1,1)$ & $\operatorname{EGARCH}(1,1)$ \\
\hline MSE & 0.00141 & 0.00168 & 0.00145 & 0.00175 \\
\hline \multirow[t]{4}{*}{ MAE } & 0.02204 & 0.02479 & 0.02346 & 0.02192 \\
\hline & \multicolumn{4}{|c|}{ Panel B: Performance during calm period } \\
\hline & \multicolumn{2}{|c|}{ USDINR } & \multicolumn{2}{|c|}{ EURINR } \\
\hline & GARCH $(1,1)$ & $\operatorname{EGARCH}(1,1)$ & GARCH $(1,1)$ & $\operatorname{EGARCH}(1,1)$ \\
\hline MSE & 0.00001 & 0.00005 & 0.00028 & 0.00027 \\
\hline MAE & 0.00178 & 0.00667 & 0.00937 & 0.00819 \\
\hline
\end{tabular}

Source: Authors' computations. 
Table 9. Model with the lower MSE/MAE.

\begin{tabular}{ccccc}
\hline & \multicolumn{2}{c}{ USDINR } & \multicolumn{2}{c}{ EURINR } \\
\hline Period & MSE & MAE & MSE & MAE \\
Entire & GARCH & EGARCH & GARCH & GARCH \\
Volatile & GARCH & GARCH & GARCH & EGARCH \\
Calm & GARCH & GARCH & EGARCH & EGARCH \\
\hline
\end{tabular}

Source: Authors' computations.

policy makers and regulators. These fluctuations in exchange rate represent the volatility of the underlying currency and building models to simulate and possibly forecast volatility is an important part of trying to manage the currency risk. In this paper, we have attempted to model the volatility of Indian rupee using rolling symmetric and asymmetric GARCH models of lower order based generalized error distribution and tested them for forecasting ability using the MSE and MAE out-of-sample forecasting tests. The leptokurtic fat-tailed nature of the USDINR and EURINR series used under the study, as discussed in the section on data description, establishes a rationale for using GED directly rather than normal distribution to estimate volatility models.

The robustness of the findings is tested by splitting the period of study into spells of tranquility and volatility. Further, DM test is used to evaluate the predictive superiority of the methods of evaluating forecasting ability of the GARCH $(1,1)$ and EGARCH $(1,1)$ models estimated for USDINR AND EURINR series using daily exchange rate data from April 2006 to January 2018.

The study has revealed that the GARCH $(1,1)$ model is a better option than the EGARCH $(1,1)$ model. This conclusion is given on the basis of the MSE loss function as GARCH $(1,1)$ exhibits a lower MSE than EGARCH $(1,1)$ in a majority of the currency-time period buckets. However, the performance of the two models is equally divided when the MAE criterion is considered.

Based on the findings of the study, even though MAE considers both models equal on forecasting performance, we recommend GARCH $(1,1)$ for volatility forecasting of Indian rupee as it is also consistent with the principle of parsimony. Other things remaining equal, parsimony is a key consideration in modelling as discussed in studies such as [52] [53] and [54]. GARCH (1,1) was also found to be best suited for models exchange rate volatility by many previous studies including those by [44] [55] [56] [57] [58] and [59]. Further, many studies have also argued against the prominence of leverage effect in the exchange rate series. ([44] [60] and [61]).

The authors have also compared the two models using log likelihood criteria, Akaike information criterion (AIC), the Bayesian information criterion (BIC) and Hannan Quinn (HQ) criterion to see if these criteria also support GARCH $(1,1)$. The findings for the immediate past five year data for both USDINR and EURINR are tabulated in Table 5. The model fit criteria also support GARCH 
$(1,1)$ model. The residual diagnostics of these models confirm that there is no $\mathrm{ARCH}$ effect and the residuals are non-normally distributed since the error distribution used for the study is GED.

The findings of the study are not applicable to currencies of other countries as all currencies have different volatility behavior. However, the methodology used by the authors is quite robust and the same can be applied for other currencies to model their volatility.

While the authors have tried to ensure robustness of findings of the study, the current study suffers from the limitation of being dependent on the data and the sample period used for the study. As in other studies of this nature, the findings of the study are based on the underlying data and any generalization of the same has to be done with adequate caution. The findings of the study are also dependent on the software used. Eviews 9 has been used for the purpose of the study and the coefficients may vary if any other software package is used.

We recommend future studies may be undertaken by using more GARCH family models and testing the findings of the current study for other currency pairs.

\section{References}

[1] Engle, R.F. (1982) Autoregressive Conditional Heteroscedasticity with Estimates of Variance of United Kingdom Inflation. Econometrica, 50, 987-1008. https://doi.org/10.2307/1912773

[2] Bollerslev, T. (1986) Generalized Autoregressive Conditional Heteroscedasticity. Journal of Econometrics, 31, 307-327. https://doi.org/10.1016/0304-4076(86)90063-1

[3] Walker, A. (2014) The World Economy in 2014 http://www.bbc.com/news/business-30400861

[4] World Economic Outlook (2017) A Firming Recovery IMF World Economic Outlook (WEO).

https://www.imf.org/en/Publications/WEO/Issues/2017/07/07/world-economic-outl ook-update-july-2017

[5] Subbotin, M.T. (1923) On the Law of Frequency of Errors. Matematicheskii Sbornik, 31, 296-301.

[6] Vee, D., Ng, C., Gonpot, P.N. and Sookia, N. (2011) Forecasting Volatility of USD/MUR Exchange Rate Using a GARCH $(1,1)$ Model with GED and Student's-T Errors. University of Mauritius Research Journal, 17, 1-14.

[7] Akaike, H. (1974) A New Look at the Statistical Model Identification. Automatic Control I.E.E.E. Transactions, 19, 716-723.

[8] Schwarz, G. (1978) Estimating the dimension of a model. The Annals of Statistics, 6, 461-464. https://doi.org/10.1214/aos/1176344136

[9] Hannan, E.J. and Quinn, B.G. (1979) The Determination of the Order of an Autoregression. Journal of the Royal Statistical Society, 41, 190-195.

[10] Willmott, C. and Matsuura, K. (2005) Advantages of the Mean Absolute Error (MAE) over the Root Mean Square Error (RMSE) in Assessing Average Model Performance. Climate Research, 30, 79-82. https://doi.org/10.3354/cr030079

[11] Chai, T., Kim, H.-C., Lee, P., Tong, D., Pan, L., Tang, Y., Huang, J., McQueen, J., 
Tsidulko, M. and Stajner, I. (2013) Evaluation of the United States National Air Quality Forecast Capability Experimental Real-Time Predictions in 2010 Using Air Quality System Ozone and NO2 Measurements. Geoscientific Model Development, 6, 1831-1850. https://doi.org/10.5194/gmd-6-1831-2013

[12] Savage, N.H., Agnew, P., Davis, L.S., Ordóñez, C., Thorpe, R., Johnson, C.E., O'Connor, F.M. and Dalvi, M. (2013) Air Quality Modelling Using the Met Office Unified Model (AQUM OS24-26): Model Description and Initial Evaluation, Geosci. Model Development, 6, 353-372. https://doi.org/10.5194/gmd-6-353-2013.

[13] Epaphra, M. (2017) Modelling Exchange Rate Volatility: Application of the GARCH and EGARCH Models. Journal of Mathematical Finance, 7, 121-143. https://doi.org/10.4236/jmf.2017.71007

[14] Diebold, F.X. and Mariano, R.S. (1995) Comparing Predictive Accuracy. Journal of Business \& Economic Statistics, 13, 253.

[15] Brooks, C. and Burke, S.P. (1998) Forecasting Exchange Rate Volatility Using Conditional Variance Models Selected by Information Criteria. Economic Letters, 61, 273-278. https://doi.org/10.1016/s0165-1765(98)00178-5

[16] Hassan, S.A. (2012) Persistence and Asymmetry in Exchange Rate Volatility. International Business and Economics Research Journal, 11, 971-976. https://doi.org/10.19030/iber.v11i9.7180

[17] Prono, T. (2017) Regular Variation of Popular GARCH Processes Allowing for Distributional Asymmetry. Working Papers-U.S. Federal Reserve Board's Finance and Economic Discussion Series, 1-10. https://doi.org/10.17016/FEDS.2017.095

[18] Mendes, B. and Accioly, V. (2017) Improving (E)GARCH Forecasts with Robust Realized Range Measures: Evidence from International Markets. Journal of Economics and Finance, 41, 631-658. https://doi.org/10.1007/s12197-017-9386-x

[19] Hayo, B. and Kutan, A.M. (2005) IMF-related News and Emerging Financial Markets. Journal of International Money and Finance, 24, 1126-1142. https://doi.org/10.1016/j.jimonfin.2005.08.007

[20] Koopman, S.J., Jungbacker, B. and Hol, E. (2005) Forecasting Daily Variability of the S\&P 100 Stock Index Using Historical, Realised And Implied Volatility Measurements. Journal of Empirical Finance, 12, 445-475. https://doi.org/10.1016/j.jempfin.2004.04.009

[21] Wu, H.X. and Shea, E.Y.P. (2011) Explaining the China Puzzle: High Growth and Low Volatility in the Absence of Healthy Financial Institutions. Paper Prepared for EcoMod2011, Azores, Portugal.

[22] Leucht, A., Kreiss, J. and Neumann, M.H. (2015) A Model Specification Test for GARCH(1,1) Processes. Scandinavian Journal of Statistics, 42, 1167-1193. https://doi.org/10.1111/sjos.12158

[23] Usman, U., Auwal, H.M. and Abdulmuhyi, M.A. (2017) Fitting the Nigeria Stock Market Return Series Using GARCH Models. Theoretical Economics Letters, 7, 2159-2176. https://doi.org/10.4236/tel.2017.77147

[24] Pilbeam, K. and Langeland, K.N. (2014) Forecasting Exchange Rate Volatility: GARCH Models versus Implied Volatility Forecasts. International Economics and Economic Policy, 12, 127-142. https://doi.org/10.1007/s10368-014-0289-4

[25] Dritsaki, C. (2017) An Empirical Evaluation in GARCH Volatility Modelling: Evidence from the Stockholm Stock Exchange. Journal of Mathematical Finance, 7, 366-390. https://doi.org/10.4236/jmf.2017.72020

[26] Zhang, K., De Mello, L. and Sadeghi, M. (2018) Evaluating Volatility Forecasts with 
Ultra-High Frequency Data-Evidence from the Australian Equity Market. Theoretical Economics Letters, 8, 1-27. https://doi.org/10.4236/tel.2018.81001

[27] Aravind, M. (2017) FX Volatility Impact on Indian Stock Market: An Empirical Investigation. Vision (09722629), 21, 284-294. https://doi.org/10.1177/0972262917716760

[28] Alegwu, F.O., Aye, G.C. and Asogwa, B.C. (2017) Asymmetric Effect of Real Exchange Rate Volatility on Agricultural Products Export: A Case Study. Economia Internazionale/ International Economics, 70, 261-279.

[29] Fišer, R., and Horváth, R. (2009) Central Bank Communication and Exchange Rate Volatility: A GARCH Analysis. Working Papers (William Davidson Institute)-University of Michigan Business School, 1-11.

[30] Singh, T. (2002) On the GARCH Estimates of Exchange Rate Volatility in India. Applied Economics Letters, 9, 391-395. https://doi.org/10.1080/13504850110086062

[31] Mondal, L. (2012) Foreign Exchange Market Intervention and Exchange Rate Volatility: A Bivariate GARCH Model for India. IUP Journal of Bank Management, 11, 29-40.

[32] Maqsood, A., Safdar, S., Shafi, R. and Lelit, N.J. (2017) Modelling Stock Market Volatility Using GARCH Models: A Case Study of Nairobi Securities Exchange (NSE). Open Journal of Statistics, 7, 369-381. https://doi.org/10.4236/ojs.2017.72026

[33] Dickey, D.A. and Fuller, WA. (1979) Distribution of the Estimators for Autoregressive Time Series with a Unit Root. Journal of the American Statistical Association, 74, 427-431.

[34] Dickey, D.A. and Fuller, W.A. (1981) Likelihood Ratio Statistics for Autoregressive Time Series with a Unit Root. Econometrica, 49, 1057-1072. https://doi.org/10.2307/1912517

[35] Phillips, P.C.B. and Perron, P. (1988) Testing for a Unit Root in Time Series Regression. Biometrika, 75, 335-346. https://doi.org/10.1093/biomet/75.2.335

[36] Lutkepohl, H. (1993) Introduction to Multiple Time Series Analysis. Springer, New York. https://doi.org/10.1007/978-3-642-61695-2

[37] Mandelbrot, B.B. (1963) The Variation of Certain Speculative Prices. The Journal of Business, 36, 394-419. https://doi.org/10.1086/294632

[38] Ljung, G. and Box, G. (1978) On a Measure of Lack of Fit in Time Series Models. Biometrika, 65, 297-303. https://doi.org/10.1093/biomet/65.2.297

[39] Ljung, G. and Box, G. (1979) The Likelihood Function of Stationary Autoregressive-Moving Average Models. Biometrika, 66, 265-270. https://doi.org/10.1093/biomet/66.2.265

[40] Nelson, D.B. (1991) Conditional Heteroscedasticity in Asset Returns: A New Approach. Econometrica, 59, 347-370. https://doi.org/10.2307/2938260

[41] Alexander, C. (2008) Practical Financial Econometrics. John Wiley \& Sons Ltd., Chichester, West Sussex.

[42] Kullback, S. and Leibler, R.A. (1951) On Information and Sufficiency. Annals of Mathematical Statistics, 22, 79-86. https://doi.org/10.1214/aoms/1177729694

[43] Clements, M.P. (2005) Evaluating Econometric Forecasts of Economic and Financial Variables. Palgrave Texts in Econometrics, Palgrave Macmillan, Houndmills.

[44] Hansen, P.R. and Lunde, A. (2005) A Forecast Comparison of Volatility Models: Does Anything Beat a GARCH(1,1)? Journal of Applied Econometrics, 20, 873-889. 
https://doi.org/10.1002/jae.800

[45] Hering, A.S. and Genton, M.G. (2011) Comparing Spatial Predictions. Technometrics, 53, 414-425. https://doi.org/10.1198/tech.2011.10136

[46] Dell'Aquila, R. and Ronchetti, E. (2004) Robust Tests of Predictive Accuracy. Metron, 62, 161-184.

[47] Lettau, M. and Ludvigson, S. (2001) Consumption, Aggregate Wealth and Expected Stock Returns. The Journal of Finance, 56, 815-849. https://doi.org/10.1111/0022-1082.00347

[48] Martens, M. (2002) Measuring and Forecasting S\&P 500 Index-Futures Volatility Using High Frequency Data. The Journal of Futures Markets, 22, 497-518. https://doi.org/10.1002/fut.10016

[49] Da Veiga, B., Chan, F. and McAleer, M. (2012) It Pays to Violate: How Effective Are the Basel Accord Penalties in Encouraging Risk Management? Accounting and Finance, 52, 95-116. https://doi.org/10.1111/j.1467-629x.2011.00422.x

[50] Alberg, D., Shalit, H. and Yosef, R. (2008) Estimating Stock Market Volatility Using Asymmetric GARCH Models. Applied Financial Economics, 18, 1201-1208. https://doi.org/10.1080/09603100701604225

[51] Karmakar, M. and Shukla, G.K. (2015) Managing Extreme Risk in Some Major Stock Markets: An Extreme Value Approach. International Review of Economics and Finance, 35, 1-25. https://doi.org/10.1016/j.iref.2014.09.001

[52] Kocenda, E. and Valachy, J. (2006) Exchange Rate Volatility and Regime Change: A Visegrad Comparison. Journal of Comparative Economics, 34, 727-753. https://doi.org/10.1016/j.jce.2006.07.003

[53] Hsieh, D. (1989) Modeling Heteroskedasticity in Daily Foreign Exchange Rates. Journal of Business and Economic Statistics, 7, 307-317.

[54] Malik, A. (2005) European Exchange Rate Volatility Dynamics: An Empirical Investigation. Journal of Empirical Finance, 12, 187-215. https://doi.org/10.1016/j.jempfin.2003.09.004

[55] Latifa, S., Omar, J. K. K. and J. M. Mutiso (2013) Garch Modelling in Monthly Foreign Exchange in Kenya. Americal Journal of Mathematical Science and Applications, 1, 13-39.

[56] Berüment, H. and Günay, A. (2003) Exchange Rate Risk and Interest Rate: A Case Study for Turkey. Open Economies Review, 14, 19-27. https://doi.org/10.1023/A:1021243101272

[57] Oduncu, A. (2011) The Effects of Currency Futures Trading on Turkish Currency Market. Journal of BRSA Banking and Financial Markets, 5, 97-109.

[58] Ngowani, A. (2012) RMB Exchange Rate Volatility and its Impact on FDI in Emerging Market Economies: The Case of Zambia. International Journal of Business and Social Science, 3, 9-15.

[59] Ullah, S., Haider, S.Z. and Azim, P. (2012) Impact of Exchange Rate Volatility on Foreign Direct Investment: A Case Study of Pakistan. Pakistan Economic and Social Review, 50, 121-138.

[60] Bollerslev, T., Chou, R.Y. and Kroner, K.F. (1992) ARCH Modeling In Finance: A Review of the Theory and Empirical Evidence. Journal of Econometrics, 39, 5-59. https://doi.org/10.1016/0304-4076(92)90064-x

[61] Olowe, R. (2011), Exchange Rate Volatility, Global Financial Crisis and the Day-of-the-Week Effect. KCA Journal of Business Management, 3, 138-149. https://doi.org/10.4314/kjbm.v3i3.72101 